\title{
Metanol-intoxikazioa: diagnostiko kliniko, analitiko eta tratamendu azkarren beharra
}

\author{
Methanol intoxication: the importance of early clinical and analytical diagnosis \\ and treatment \\ Beñat de Alba Iriarte ${ }^{1 *}$, Noelia Lopez Barba ${ }^{1}$, Eztitxu Gaztelumendi Eguiguren ${ }^{2}$, Felix Zubia \\ Olascoaga ${ }^{3}$, Maria Asuncion Vives Almandoz ${ }^{1}$, Eva Lorea Gil Rodriguez ${ }^{1}$, Miren Arantza \\ Aguillo Garcia ${ }^{2}$, Jesus Barado Hualde ${ }^{1}$ \\ ${ }^{1}$ Donostia Unibertsitate Ospitaleko Analisi Klinikoen Zerbitzua \\ ${ }^{2}$ Donostia Unibertsitate Ospitaleko Larrialdi Zerbitzua \\ ${ }^{3}$ Donostia Unibertsitate Ospitaleko Zainketa Intentsiboen Unitatea
}

benat.dealbairiarte@osakidetza.eus

\section{Laburpena}

Metanol-intoxikazioa morbilitate handia duen egoera da, nahasmendu metaboliko larriak, itsutasuna eta disfuntzio neurologiko garrantzitsuak eragin ditzakeena. Hori dela eta, diagnostikoa eta tratamendua garaiz ezarri behar dira. Azkenaldian, metanol-intoxikazio kasuen hazkundea antzeman dugu gure ingurunean (\% 50 azken urtean) eta gure ospitalean, gehientsuenetan bezala, ez dago metanola neurtzeko analisi-teknikarik eskuragarri.

Horregatik, artikulu honetan ospitalean berriki izan diren lau kasu kliniko aurkezten ditugu, gaixo hauen maneiuari eta datu kliniko eta analitikoei dagokien informazio garrantzitsuena aztertuz. Gure helburua zera da: batzuetan zehazten zaila den diagnostiko goiztiarra ezartzeko estrategia baliagarria garatzea.

Intoxikazio mota honen hilkortasun-tasa handia izanik eta tratamendua badagoela jakinik, metanolintoxikazioa berehala identifikatzea garrantzitsua da. Azaldutako kasu klinikoak aztertu ondoren, emaitzek adierazi zuten susmo kliniko handia, azidosi metabolikoa eta anion gap eta osmol gap altuak diagnostiko goiztiarra egitea ahalbidetzen duten ezaugarriak direla.

Gako-hitzak: metanol, intoxikazio, azidosi metaboliko, anion gap, osmol gap

\section{Abstract}

Methanol intoxication is an infrequent condition associated with high morbidity that can cause severe metabolic disturbances, blindness, and important neurological dysfunction potentially life threatening. Therefore, early diagnosis and treatment is required to obtain the best possible result for the patient. Recently, an increase in cases of methanol intoxication has been observed in our environment $150 \%$ in the last year) and in our hospital, as in most of them, specific analysis techniques for methanol are not available.

This is why in this article we present four recent clinical cases that occurred in our hospital: to analyze the most relevant information derived from the management of these patients and their clinical and 
Beñat de Alba I., Noelia Lopez B., Eztitxu Gaztelumendi E., Felix Zubia O., Ma Asuncion Vives A., Eva Lorea Gil R., Miren Arantza Aguillo G., Jesus Barado H.

laboratory data. Our objective is to develop a valid strategy in order to facilitate obtaining an early diagnosis sometimes difficult to achieve.

Due to the potential mortality of this poisoning and the existence of treatment, it is important to recognize methanol intoxication immediately. After analyzing the exposed clinical cases, the results indicated that a high index of suspicion and the presence of metabolic acidosis associated with an elevated anion gap and osmol gap and are characteristic findings that allow an early diagnosis.

Keywords: methanol, intoxication, metabolic acidosis, anion gap, osmol gap

Bidalia: 20.12.11

Onartua: 2021.01.13

http://doi.org/10.26876/osagaiz.1.2021.346

\section{Sarrera}

Metanola $\left(\mathrm{CH}_{3} \mathrm{OH}\right)$, alkohol metiliko, egur-alkohol edo erretzeko alkohol moduan ere ezaguna, likido kolorge eta lurrunkorra da giro-tenperaturan. Haren erabilera ohikoa da industriako, laborategiko eta etxeko produktuetan, hainbat substantziaren osagai gisa (izotz-aurkakoak, disolbatzaileak eta erregaiak). Berez ez du arriskurik sortzen, baina haren metabolitoak oso toxikoak dira (1). Metanolaren ingestioak, arnasteak edo larruazaleko kontaktuak pozoitzeak eragin ditzake. Metanol-intoxikazio kasuak bakanak diren arren, hilkortasuna altua izan ohi da. Kasu arin gehienak metanola arnastearen ondorioz gertatzen dira, baina oharkabean igarotzen dira. Alkoholdun edari adulteratuen ekoizpenean metanolak duen erabilera klandestinoak, ordea, pozoitze-kasu oso larriak eragiten ditu normalean, eta horrelakoak dira ospitaleetan eta osasun-zentroetan gehien nabarmentzen direnak. Metanolaren eragin toxikoen aurrean sentikortasuna aldakorra da, intoxikazio larria eragiteko metanola kopuru txikian hartzea nahikoa den arren. Toxikotzat eta hilgarritzat hartzen den dosian aldakortasun handia dago, nahiz eta aditu gehienek dosi hilgarritzat $30 \mathrm{~mL}$ metanol puru jotzen duten $(1,2)$.

Intoxikazioak, ustekabekoa zein suizida izan, morbilitate- eta hilkortasun-tasa (\% 25-50) oso handia du, kasu gehienetan, diagnostikoa zehazteko zailtasunak direla eta, tratamenduaren hasiera atzeratzen baita. Sintomen hasiera aldakorra izaten da eta normalean lehenengo 12-24 orduetan hasten dira agertzen. Kasu arinak etanol-intoxikazioaren antzekoak dira, baina metanol-pozoitze kasu larriagoek ondorio gastrointestinal, bisual eta neurologiko kaltegarriak eragiten dituzte, baita heriotza ere, tratamendua azkar ezartzen ez bada. Diagnostikoa zehazteko pazientearen aurrekariak, egoera klinikoa eta laborategiko analisien emaitzak hartu behar dira kontuan. Metanol-mailaren odoleko neurketa egitea da diagnostikoa konfirmatzeko era, baina gure ospitalean, gehientsuenetan bezala, ez dago metanola neurtzeko analisiteknikarik eskuragarri. Horregatik, beste baliabide analitiko eraginkor batzuk erabiltzen ditugu metanol-intoxikazioaren diagnostikoa zehazteko: anion gap eta osmol gap kalkuluak.

Susmo kliniko eta analitikoan soilik oinarrituta jar daiteke presazko tratamendua, anion gap eta osmol gap emaitzak jakinda, metanol-balioaren baieztapenaren zain egon gabe. Neurri terapeutikoak lehenbailehen ezartzea funtsezkoa da kalteak mugatzeko eta gaixoaren balizko susperraldia ahalbidetzeko. Tratamenduaren oinarria hauxe da: azidosia zuzentzea, konplikazioen terapia sintomatikoa, metanola metabolito toxikoetan eraldatzea oztopatzeko antidotoa ematea, eta metanola eta metabolitoak iraiztea. Horretarako, neurri terapeutiko orokorrez gain, etanola edo fomepizola antidoto gisa, bikarbonatoa, azido folikoa eta hemodialisia erabiltzen dira $(1,2,3,4)$.

Azkenaldian, metanol-intoxikazio kasuak areagotu egin dira gure ingurunean. Gure ospitalean, esaterako, bikoiztu egin dira metanol bidezko nahitako pozoitze-kasuak duela bost urtetik hona. Urtean kasu bakarra edo bi egotetik, hiruzpalau metanol-intoxikazio kasu artatzera igaro gara. Intzidentziaren igoera horretan biztanleriaren arazo ekonomiko eta psikologikoek eragin 
nabarmena izan dute, hainbatek ohiko edari alkoholdunak kontsumitu beharrean produktu merkeagoak hartzeko joera izan baitute, metanoldun edari adulteratuak adibidez. Ospitalean ikusitako kasuen maneiuan antzemandako zailtasunak direla eta, ebaluazio diagnostikoa behar bezala eta ahalik eta azkarren egitearen garrantzia azpimarratu nahi dugu.

Lan honetan gure ospitalean azken bi urteetan diagnostikatutako lau kasu arras ezberdin bildu ditugu, bakoitzaren berezitasunak nabarmentzeko asmoz eta etorkizunean egon litezkeen metanol-intoxikazio kasuen maneiuaren lagungarri gisa.

\section{Kasuen aurkezpena}

\section{Lehen kasua}

Alkoholismo konpultsiboaren aurrekariak zituen 48 urteko emakumea bere osasun-zentrotik Larrialdi Zerbitzura bideratu zuten metanol-intoxikazioaren susmopean. Haren bikotekideak jakinarazi zuen bezperan alkohol-intoxikazioarekin bateragarriak ziren zantzuak zituela eta egunsentian, 12 orduren ostean, ataxiko, hizkera desegokia erabiliz eta ikusmen lausotua izanik esnatu zela. Etxean ez zuen alkoholdun edaririk aurkitu, alkohol metiliko botila huts bat besterik ez.

Hasierako azterketan, kontzientzia-mailaren jaitsiera, Kussmaul arnasketa, larruazal hotza eta zianosia nabarmendu ziren (tentsio arteriala $150 / 100 \mathrm{mmHg}$, tenperatura $31,5{ }^{\circ} \mathrm{C}$, takipnea eta $\mathrm{O}_{2}$ saturazioa \% 97). Elektrokardiograma eta toraxeko erradiografia normalak izan ziren. Ez zuen begirik irekitzen, ez hitzez erantzuten, ezta mugimendu-erantzunik ere. Midriasi arreaktibo bilaterala aurkitu genion.

Odol-analisia egin zitzaion. Gasometrian azidosi metaboliko larria aurkitu zen: $\mathrm{pH}<6,8$; bikarbonato kalkulaezina; laktatoa 7,1 mmol/L; sodioa $147 \mathrm{mmol} / \mathrm{L}$; kloroa $105 \mathrm{mmol} / \mathrm{L}$; potasioa 4,21 mmol/L. Biokimikan eta hemograman emaitza hauek nabarmendu ziren: glukosa $158 \mathrm{mg} / \mathrm{dL}$; urea $20 \mathrm{mg} / \mathrm{dL}$; laktato deshidrogenasa $1.043 \mathrm{U} / \mathrm{L}$; alanina aminotransferasa (ALT) $668 \mathrm{U} / \mathrm{L}$; etanola $<0,1 \mathrm{~g} / \mathrm{L}$; leukozitosia $11,03 * 10^{3} / \mu \mathrm{L}$. Anion gap (46 mmol/L) eta osmol gap (90 mOsm $/ \mathrm{kg}$ ) emaitza altuak izan zituen [Erreferentzia-balioak 1. taulan daude]. Laborategiko gainerako parametroak normalak ziren. Emaitza horiek ikusita, metanol-intoxikazioaren susmoa sendotu zen eta pazientea Zainketa Intentsiboko Unitatera (ZIU) lekualdatu genuen tratamendua jaso zezan: aireztapen mekanikoa, serum fisiologikoa, zainbarneko etanola antidoto gisa, bikarbonatoa, azido folikoa eta metanol molekulak garbitzeko hemodialisia. Sei orduz hemodialisia hartu eta gero, azidosi metabolikoa zuzendu zen eta etanol bidezko tratamendua kentzea erabaki genuen.

Behin betiko diagnostikoa gas-kromatografia bidez metanolaren plasma-maila neurtuta konfirmatu zen: 3,062 g/L metanol (erreferentzia-balioa: maila toxikoa $>0,2 \mathrm{~g} / \mathrm{L}$ ). Harrigarria izan zen, hartutako metanol kantitatea handia izan arren, emakumea suspertu egin zen. Lau orduz hemodialisia egin ostean ateratako bigarren odol-lagin baten analisiaren emaitza 0,324 $\mathrm{g} / \mathrm{L}$ metanol izan zen. Zenbait orduz metabolizatzen egon ostean eta 4 orduko tratamendua hartu eta gero, metanola ia ez zen antzeman ere egin emakumearen odolean. Datu horiek metanol-intoxikazioaren ezaugarri analitikoak hobeto ulertzen lagundu ziguten, haren detekzio azkarrari garrantzia emanez.

\section{Bigarren kasua}

64 urteko gizona, ohiko edalea, oso larri ospitaleratu zuten, goizaldeko ordu txikietan. Familiaren arabera, 3 egun zeramatzan alkohola edaten. Kontzientzia-mailaren okertzea, gorakoak eta logalea izan zituen.

Larrialdi Zerbitzuan egindako azterketan, kontzientzia-mailaren jaitsiera, agonia-korrokak, larruazal hotza eta deshidratazioa nabarmendu ziren (tentsio arteriala 100/80 mm Hg, tenperatura $33,8{ }^{\circ} \mathrm{C}$ eta $\mathrm{O}_{2}$ saturazioa \% 97). Bere egoera oso larria zen, Glasgow eskala 3/15 
izanik, eta midriasi arreaktibo bilaterala aurkitu genion. Bat-batean, bihotz-biriketako gelditzea izan zuen eta bizkortzeak 20 minutu iraun zuen pultsua berreskuratu zuen arte. Garuneko eta toraxeko tomografia konputarizatuak normalak izan ziren.

Odol-analisian, alde batetik, azidosi metaboliko larria aurkitu zen gasometrian: $\mathrm{pH}$ 6,86; bikarbonatoa $7 \mathrm{mmol} / \mathrm{L}$; laktatoa $>20 \mathrm{mmol} / \mathrm{L}$; sodioa $146 \mathrm{mmol} / \mathrm{L}$; kloroa $80 \mathrm{mmol} / \mathrm{L}$; potasioa $5,01 \mathrm{mmol} / \mathrm{L}$. Biokimikan eta hemograman, bestalde, honako emaitzak nabarmendu ziren: glukosa $255 \mathrm{mg} / \mathrm{dL}$; urea $93 \mathrm{mg} / \mathrm{dL}$; NT-proBNP1.779 pg/mL; alanina aminotransferasa (ALT) 74 $\mathrm{U} / \mathrm{L}$; kreatina kinasa (CK) $1.191 \mathrm{U} / \mathrm{L}$; etanola $<0,1 \mathrm{~g} / \mathrm{L}$; leukozitosia $18,57 * 10^{3} / \mu \mathrm{L}$. Anion gap (64 mmol/L) altua neurtu zen, baina ezin izan genuen osmol gap balioa zehaztu, osmometro bidez kalkulatzen den osmolalitate neurtuaren datuak falta zirelako [Erreferentzia-balioak 1. taulan daude].

Gizonaren osasun-bilakaera latza izan zen. Botika basoaktiboak eta arnas euskarria jarri genizkion, baina tratamendu osteko erantzuna eskasa izan zen: odol-analisiko emaitzetan koagulopatia eta giltzurruneko gutxiegitasun akutua antzeman ziren. Serum-terapia, bikarbonatoa eta medikamentu baso-uzkurtzaileak emanez saiatu ginen, baina shocka eta azidosi metabolikoa ez ziren oneratu. Haren aurrekariak, ezaugarri klinikoak, azidosi metabolikoa eta anion gap altu iraunkorra kontuan hartuta, metanol-intoxikazioa izan zitekeela susmatu genuen. Hortaz, zainbarneko etanol-tratamendua, bikarbonatoa, azido folikoa eta hemodialisia jartzea erabaki genuen. Terapia gorabehera, bilakaera txarra izan zuen, arnas gutxiegitasun akutua eta shock iraunkor itzulezina areagotuz. Ordu gutxira hil egin zen.

Autopsia-txostenak odolean 0,006 g/L metanol maila zehaztu zuen. Emaitza oso baxua izanik, diagnostikoa ezin izan zen baieztatu, baina metanol-intoxikazioaren susmoak oso handia izaten segitzen du: Metanol-ingestioa gertatu zenetik, organismoak hiru egun eraman zitzakeen metanola metabolizatzen. Gainera, aztertutako odol-lagina gizona ospitaleratu eta lau ordu beranduago atera zenez, tratamenduak horrezkero bere lana egina izan zezakeen metanola gorputzetik ezabatuta.

\section{$\underline{\text { Hirugarren kasua }}$}

Egoera orokor eskasa zuen 57 urteko gizona Larrialdi Zerbitzuan artatu genuen. Bi egun lehenago, sukarra eta faringitis akutua zela eta, azitromizina hartu zuen, baina ez zuen hobekuntzarik nabaritu.

Hasierako azterketan, larruazal hotza eta perfusio eskasa antzeman genizkion. Haren egoera kaskarra zen, Glasgow eskala 8/15 izanik, eta midriasi arreaktibo bilaterala zuen. Hiru bihotzbiriketako gelditze izan zituen, horietatik errekuperatu zen eta ZIUra bideratu genuen shock septikoa susmatuz. Sabel biguna zuen, peritoneo-narritaduraren zantzurik gabekoa, eta ez zuen infekzio-fokurik edo bestelakorik iradokitzen zuen beste zantzurik.

Odol-analisiko gasometriaren emaitzek azidosi metaboliko larria adierazi zuten: $\mathrm{pH}<6,8$; bikarbonato kalkulaezina; laktatoa 12,6 mmol/L; sodioa $142 \mathrm{mmol} / \mathrm{L}$; kloroa $98 \mathrm{mmol} / \mathrm{L}$; potasioa $5,3 \mathrm{mmol} / \mathrm{L}$. Anion gap $(44 \mathrm{mmol} / \mathrm{L})$ altua zen. Biokimikaren, hemogramaren eta koagulazioaren emaitzak, ordea, normalak izan ziren. Hainbat orduren ondoren tratamenduak azidosi metabolikoa irauli ez zuela ikusita, eta $\mathrm{pH}$ baxua eta anion gap altua mantentzen zirela eta, metanol-intoxikazioa susmatu genuen. Antidoto gisa zainbarneko etanola ezarri genuen eta osmol gap kalkulatu genuen (126 mOsm $/ \mathrm{kg})$, emaitza oso altua adierazten zuena [Erreferentzia-balioak 1. taulan daude].

Datu bila, familiarekin hitz egin genuen gaixoaren egoera larriaren berri emateko. Jakinarazi ziguten aldizka alkohola hartzen zuela eta etxean alkohol metiliko botila bat erdi hutsik aurkitu zutela. Hala eta guztiz ere, intoxikazioaren tratamendu espezifikoan ahalegin handia egin arren, gizonaren osasun-bilakaera oso txarra izan zen eta bi egun beranduago hil zen. 
Metanol-intoxikazioaren susmoa gas-kromatografia bidez metanolaren plasma-maila neurtuta konfirmatu zen: 5,029 g/L metanol. Emaitza hori oso altua da eta horrek pazienteak metanol kantitate handia hartu zuela adierazten du. Behin betiko diagnostikoa metanol-intoxikazioaren ondoriozko garun-heriotza izan zen.

1. taula. Lau kasuen lehenbiziko odol-analisien emaitzak

\begin{tabular}{|c|c|c|c|c|c|}
\hline \multirow{2}{*}{ Parametroak (Unitateak) } & \multicolumn{4}{|c|}{ Emaitzak } & \multirow{2}{*}{$\begin{array}{l}\text { Erreferentzia- } \\
\text { balioak }\end{array}$} \\
\hline & 1. kasua & 2. kasua & 3. kasua & 4. kasua & \\
\hline pH & $<6,8$ & 6,86 & $<6,8$ & $<6,8$ & {$[7,35-7,45]$} \\
\hline Bikarbonatoa (mmol/L) & kalkulaezina & 7 & kalkulaezina & 5 & {$[21-28]$} \\
\hline Laktatoa (mmol/L) & 7,1 & $>20$ & 12,6 & $>20$ & {$[0,30-2,00]$} \\
\hline Sodioa $(\mathrm{mmol} / \mathrm{L})$ & 147 & 146 & 142 & 143 & [135 - 145] \\
\hline Kloroa (mmol/L) & 105 & 80 & 98 & 89 & [93 - 110] \\
\hline Potasioa (mmol/L) & 4,21 & 5,01 & 5,3 & 5,8 & {$[3,3-5,1]$} \\
\hline Glukosa (mg/dL) & 158 & 255 & 256 & 292 & [70 - 110] \\
\hline Urea (mg/dL) & 20 & 93 & 54 & 11 & {$[10-65]$} \\
\hline Laktato deshidrogenasa (U/L) & 1.043 & - & - & - & {$[135-250]$} \\
\hline $\begin{array}{l}\text { Alanina aminotransferasa } \\
(\mathrm{U} / \mathrm{L})\end{array}$ & 668 & 74 & - & 205 & [0 - 33] \\
\hline $\mathrm{T}$ troponina(ng/L) & - & - & - & 111 & [0 - 14] \\
\hline NT-proBNP (pg/mL) & - & 1.779 & - & 2.481 & [0 - 300] \\
\hline Kreatina kinasa $(\mathrm{U} / \mathrm{L})$ & - & 1.191 & - & - & [0 - 189] \\
\hline Leukozitoak $\left(* 10^{3} / \mu \mathrm{L}\right)$ & 11,03 & 18,57 & 21,64 & 10,80 & {$[3,8-10]$} \\
\hline Anion gap (mmol/L) & 46 & 64 & 44 & 49 & {$[8-16]$} \\
\hline $\begin{array}{l}\text { Osmolalitate neurtua } \\
\qquad(\mathrm{mOsm} / \mathrm{kg})\end{array}$ & 384 & - & 444 & 336 & [282 - 300] \\
\hline $\begin{array}{l}\text { Osmolalitate kalkulatua } \\
\qquad(\mathrm{mOsm} / \mathrm{kg})\end{array}$ & 294 & 310 & 318 & 316 & [275 - 301] \\
\hline Osmol gap (mOsm/kg) & 90 & - & 126 & 20 & {$[<10]$} \\
\hline Etanola (g/L) & $<0,1$ & $<0,1$ & - & 0,33 & - \\
\hline Metanola (g/L) & 3,062 & 0,006 & 5,029 & 0,021 & {$[0-0,005]$} \\
\hline
\end{tabular}


Beñat de Alba I., Noelia Lopez B., Eztitxu Gaztelumendi E., Felix Zubia O., Ma Asuncion Vives A., Eva Lorea Gil R., Miren Arantza Aguillo G., Jesus Barado H.

\section{Laugarren kasua}

46 urteko gizonezkoa desorientatuta eta mugimendu tonikoak eginez aurkitu zuten edari alkoholdunak saltzen diren saltoki batzuen inguruan eta berehala Larrialdi Zerbitzuei hots egin ziguten.

Ospitalean egin genion lehen azterketan ingurutiko deskonexioa, larruazal hotza, hepatomegalia, esplenomegalia, gorputzaren tonuaren galera, gorputz-adarren mugimendu tonikoak eta midriasia aurkitu ziren (odol-presioa $80 / 50 \mathrm{~mm} \mathrm{Hg}$ eta $\mathrm{O}_{2}$ saturazioa \% 93). Bihotz-biriketako gelditzea izan zuen eta, suspertze-maniobrak eginez eta adrenalina eta midazolam jarri ostean, pultsua berreskuratu zuen.

Odol-analisia egin zitzaion. Gasometrian azidosi metaboliko larria aurkitu zen: pH $<6,8$; bikarbonatoa $5 \mathrm{mmol} / \mathrm{L}$; laktatoa $>20 \mathrm{mmol} / \mathrm{L}$; sodioa $143 \mathrm{mmol} / \mathrm{L}$; kloroa $89 \mathrm{mmol} / \mathrm{L}$; potasioa $5,8 \mathrm{mmol} / \mathrm{L}$. Biokimikan eta hemograman emaitza hauek nabarmendu ziren: glukosa $292 \mathrm{mg} / \mathrm{dL}$; urea $11 \mathrm{mg} / \mathrm{dL}$; NT-proBNP $2.481 \mathrm{pg} / \mathrm{mL}$; T troponina $111 \mathrm{ng} / \mathrm{L}$; alanina aminotransferasa (ALT) $205 \mathrm{U} / \mathrm{L}$; etanola $0,33 \mathrm{~g} / \mathrm{L}$; leukozitosia $10,80 * 10^{3} / \mu \mathrm{L}$. Anion gap (49 mmol/L) eta osmol gap (20 $\mathrm{mOsm} / \mathrm{kg}$ ) emaitza altuak izan zituen [Erreferentzia-balioak 1. taulan daude]. Emaitza horiek eskutan, metanol-intoxikazioa susmatu genuen eta ZIUan tratamendua jarri genion: zainbarneko etanola, bikarbonatoa, azido folikoa eta hemodialisia. Hala ere, gaixoa ordu gutxiren buruan hil zen.

Metanol emaitza 0,021 g/L izan zen, diagnostikoa konfirmatuz.

\section{Eztabaida}

Metanola azkar xurgatzen da organismoan eta erraz zeharkatzen du barrera hematoentzefalikoa. Kontzentrazio plasmatiko maximoa 30-60 minututan lortzen da eta erdibizitza 12 eta 24 ordu bitartekoa da. Metabolismo endogenoaren ondorioz, arnasketaren bidez jariatzen da metanolaren ehuneko txiki bat. Tratamendua hartu gabeko intoxikatuetan $\% 5$ baino gutxiago giltzurrun bidez iraizten da eta gainerakoa gibelean metabolizatzen da: metanola alkohol deshidrogenasaren bidez oxidatzen da formaldehidoa sortuz; formaldehidoa, formaldehido deshidrogenasaren bidez, azido formiko bihurtzen da; eta azido formikoa, folatoaren menpeko oxidazioaren bidez, karbono dioxido eta ur bilakatzen da azkenik (1. irudia). Metanola berez ez da toxikoa; eragin toxikoa sortutako metabolito kantitatearen araberakoa da (5).Bi metabolito horiek, formaldehidoa eta azido formikoa, dira metanolaren eragin toxikoaren erantzuleak, azido formikoa izanik begi-toxikotasunaren, azidosi metabolikoaren eta anion gap altuaren kausa nagusia. Orduak igaro ahala, laktatoa sor daiteke azidosi metabolikoa areagotuz.

1. irudia. Metanolaren metabolizazio-prozesua.

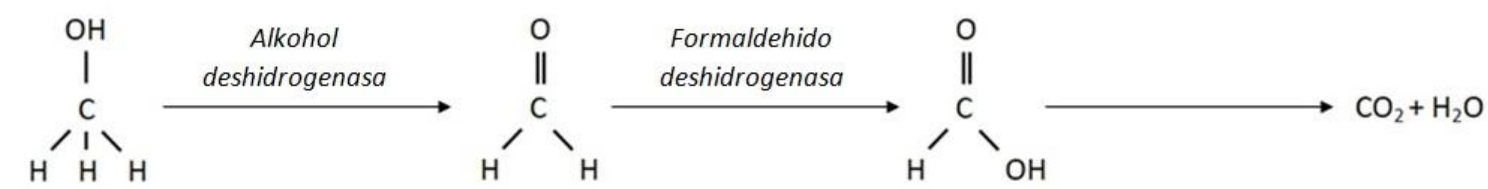

Metanola

Formaldehidoa

Azido formikoa

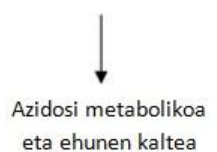


Sintomen hasiera oso aldakorra da eta intoxikatzeko moduaren, metanol-kontzentrazioaren eta esposizio-denboraren araberakoa da. Intoxikazioaren ondoriozko sintomak 30 minutu eta 72 ordu bitartean has daitezke, nahiz eta kasu gehienetan lehenengo 12-24 orduetan nabaritzen diren, hori baita metanola bere metabolitoetan biotransformatzeko beharrezkoa den denbora. Metanola etanolarekin batera irensten bada, sintomak beranduago hasiko dira. Hilkortasun-tasa \% 25-50 bitartekoa da eta heriotza saihestea lortzen den kasuetan ondorio neurologiko eta bisual garrantzitsuak sor daitezke, itsutasuna barne $(6,7)$.

Metanol-intoxikazioaren zeinuek eta sintomek eragin desberdinak izan ditzakete eta honela multzoka daitezke:

- Ondorio neurologikoak: Intoxikazio-kasu arinetan, buruko mina, zorabioa, letargia, ataxia edo etanol-intoxikazioaren antzeko egoera; kasu larrietan, konbultsioa, koma eta garuneko edema. Neurotoxikotasuna azido formikoak zitokromo oxidasa inhibitu ostean eragiten duen hipoxiaren emaitza da.

- Ondorio bisualak: Ikusmen-zorroztasunaren bat-bateko galera, nistagmoa, begi-ninien erreflexu-aldaketak, midriasia, papiledema eta behin betiko itsutasuna ikusmennerbioaren atrofiaren eraginez.

- Ondorio gastrointestinalak: Metanola apur bat narritagarria da eta goragalea, oka eta sabeleko mina eragiten ditu; intoxikazioak luze irauten badu, pankreatitis akutuaren datu kliniko eta entzimatikoak antzeman daitezke.

Metanolak ez du biriketako toxikotasunik eragiten, arnasten denean izan ezik.

Metanol-intoxikazioa susmatzeko pazientearen aurrekariak, egoera klinikoa eta laborategiko analisien emaitzak hartu behar dira kontuan. Datu bereizgarriena anion gap altua ( $>16 \mathrm{mmol} / \mathrm{L})$ duen azidosi metabolikoa da; beraz, emaitza analitiko hori ageri den egoera guztietan susmatu beharko litzateke $(8,9)$.

Diagnostikoa odol-lagin batean metanol-maila neurtuz konfirmatzen da, baina ospitale gehientsuenetan ez dago metanola neurtzeko analisi-teknikarik eskuragarri. Hala ere, sintoma bateragarriak, azidosi metabolikoa eta anion gap emaitza altua duten ustezko metanolintoxikazio kasuetan, beste datu analitiko baten neurketa erabil daiteke diagnostikoa lehenbailehen baieztatzeko: osmol gap (2. irudia). Osmol gap emaitza altua izateak odolean substantzia osmotikoki aktiboak daudela adierazten du, hala nola alkoholak (metanol, etilenglikol), azukreak (manitol, sorbitol), lipidoak (hipertriglizeridemia) edo proteinak (hipergammaglobulinemia). Hori dela eta, osmol gap balioa toxikoak identifikatzeko azterketatresna gisa erabiltzen da eta, aurretik aipatutako datu kliniko eta analitikoekin batera, neurri erabakigarria da metanol-intoxikazioaren diagnostikoa orientatzen eta tratamendua azkar ezartzen laguntzeko. Gainera, haren kalkuluak metanolaren gutxi gorabeherako odolkontzentrazioa kalkulatzeko ere balio dezake (osmol gap x 0,032, g/L-tan).

Hala eta guztiz ere, osmol gap balioa aldatu egiten da orduek aurrera egin ahala metanolintoxikazio kasuetan: lehen orduetan, metanolarekiko esposizioa izan eta gutxira, osmol gap emaitza altua da; baina hurrengo orduetan, metanola azido formikoan metabolizatzen denez, osmol gap emaitza normalizatu egiten da. Anion gap balioarekin alderantziz gertatzen da: denbora igaro ahala anion gap balioa handitzen da, osmol gap balioa txikitzen den bitartean (3. irudia). Horregatik, metanolarekiko esposizioa gertatu eta ordu batzuetara, osmol gap balioa normalizatuta ager daiteke eta haren neurketak emaitza negatibo faltsua eta, ondorioz, diagnostikoan akatsa ekar dezake. Osmol gap eta anion gap balioak aldatzeko igarotzen den denbora aldakorra izaten da. Faktore hauen menpe dago batez ere: hartutako metanol kantitatea, metanola hartu denetik igaro den denbora-tartea, gorputzean izaten duen metabolizazio-prozesuaren abiadura eta tratamendua ezartzen den unea. Eskuarki 12-24 ordu bitartean igaro daitezke osmol gap emaitza normaldu arte, baina hartutako metanol kantitatea 
Beñat de Alba I., Noelia Lopez B., Eztitxu Gaztelumendi E., Felix Zubia O., Ma Asuncion Vives A., Eva Lorea Gil R., Miren Arantza Aguillo G., Jesus Barado H.

handia bada eta tratamendua berandu hasi bada adibidez, ordu gehiago beharko dira osmol gap balioa normalizatzeko, 24 ordutik gora. Azkarrago normalizatzen da osmol gap balioa metanol kantitate txikien ondoriozko pozoitzeetan eta tratamendua bizkor ezarri bada, 12 ordu baino lehen. Ustezko metanol-intoxikazio kasu guztietan metanola odolean neurtuz konfirmatu behar da diagnostikoa. Emaitza positiboa izan ohi da esposizioaren ondorengo 24 orduetan jasotako odol-laginen analisian, baina negatiboa izan daiteke beranduago eskuratutako laginetan, metanolaren degradazioaren ondorioz $(10,11)$.

Anion gap $(\mathrm{mmol} / \mathrm{L})=\left[\mathrm{Na}^{+}\right]-\left[\mathrm{Cl}^{-}\right]+\left[\mathrm{HCO}_{3}{ }^{-}\right]$

[erreferentzia-balioa: $8-16 \mathrm{mmol} / \mathrm{L}$ ]

Osmol gap (mOsm/kg) : Odoleko neurtu gabeko solutu ezezagunak

$$
\text { Osmol gap }=\left[\begin{array}{c}
\text { Osmolalitate } \\
\text { neurtua }
\end{array}\right]-\left[\begin{array}{c}
\text { Osmolalitate } \\
\text { kalkulatua }
\end{array}\right]
$$

[erreferentzia-balioa : $<10 \mathrm{mOsm} / \mathrm{Kg}$; balio kritikoa: $>15 \mathrm{mOsm} / \mathrm{kg}$ ]

Osmolalitate neurtua: Odoleko osmotikoki aktiboak diren solutu guztiak

Osmolalitate kalkulatua: Odoleko osmotikoki aktiboak diren esperotako solutuak

$\begin{gathered}\text { Osmolalitate } \\ \text { kalkulatua }\end{gathered}=2 \times\left[\mathrm{Na}^{+}\right]+2 \times\left[\mathrm{K}^{+}\right]+\frac{[\text { Urea] }}{6}+\frac{\text { [Glukosa] }}{18}$

$\left[\mathrm{Na}^{+} m m o l / L\right.$-tan; $\mathrm{K}^{+} m m o l / L$-tan; Urea $m g / d L$-tan; Glukosa $m g / d L$-tan]

2. irudia. Anion gap eta osmol gap kalkuluak.

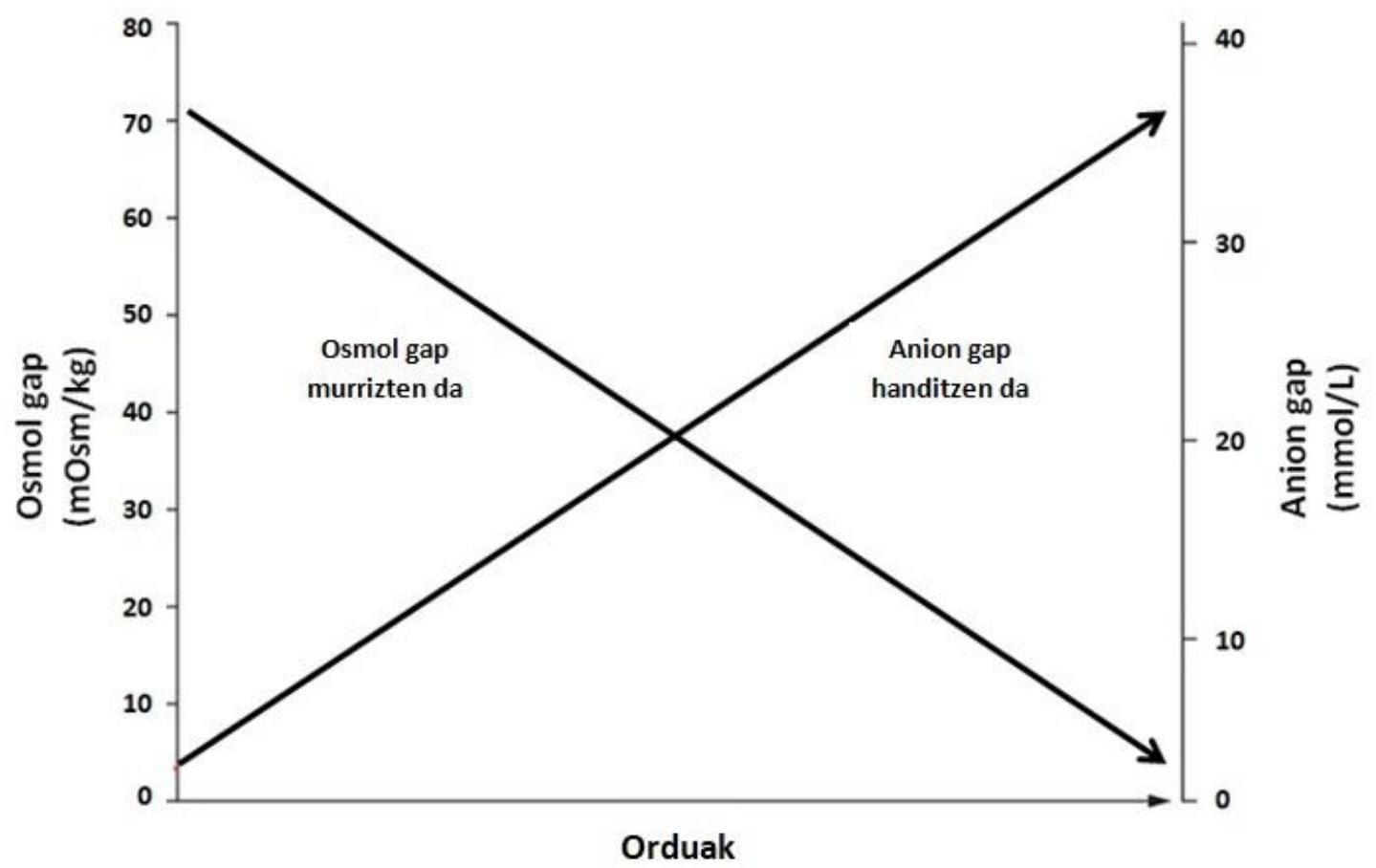

3. irudia. Osmol gap eta anion gap balioen aldaketa denboran zehar. 
Intoxikazioaren larritasuna odoleko metanol-mailaren arabera sailkatzen da eta honela erlazionatzen da ezaugarri klinikoekin (12):

- Intoxikazio arina: 0,2 g/L-tik beherako metanolemia. Nekea, goragalea, epigastralgia, buruko mina eta ikusmen-pertzepzioaren asaldurak.

- Intoxikazio moderatua: 0,2-0,5 g/L arteko metanolemia. Oka, mozkorraldiaren zantzuak, batez ere metanola etanolarekin nahastuta hartu bada, larruazal zurbil, hotz eta izerditsua, ikusmen lausoa eta takipnea, azidosi metabolikoa arnasketa bidez konpentsatzen saiatzeagatik.

- Intoxikazio larria: 0,5 g/L-tik gorako metanolemia. Arnasketa azkar eta sakonekoa, konbultsioak, zianosia, hipotentsioa, papiledema, midriasia eta koma.

$1 \mathrm{~g} /$ L-tik gorako metanolemia balio hilgarritzat hartzen da.

Diagnostiko diferentziala egiteko azidosi metabolikoa eta anion gap balio altua duten egoera guztiak hartu behar dira kontuan (etilenglikol-intoxikazioa, salizitato-intoxikazioa, zetoazidosi alkoholikoa, etab.) $(13,14)$.

Pazientearen bilakaera gehiago erlazionatzen da azidosiaren larritasunarekin metanolaren odoleko kontzentrazioarekin baino, horregatik azidosi metabolikoa hurbiletik zaindu behar da. Pronostikoa hobea da hartutako metanol-dosia denboran zehar banatua izan bada, etanolarekin nahastuta hartu bada edo tratamendu egokia garaiz ezarri bada (15).

Intoxikazio mota honen hilkortasun-tasa handia dela eta, diagnostikoa garaiz zehazteaz gain tratamendua ahalik eta azkarren ezartzea gomendatzen da. Arretak berehalakoa izan behar du. Neurri terapeutikoen artean daude azidosia zuzentzea, konplikazioen tratamendu sintomatikoa, etanola ematea antidoto gisa metanola metabolito toxikoetan eraldatzea oztopatzeko eta hemodialisi bidez metanola eta metabolitoak iraiztea. Arnasketa bermatzeko euste-neurriak erabil daitezke, aireztapen mekanikoa adibidez, eta oreka hidroelektrolitikoa eta gernuiraizketa egokiak mantentzeko zainbarneko medikamentuak, behar izanez gero. Urdailgarbiketa ingestio osteko lehen bi orduetan baino ez da eraginkorra. Ikatz aktibatua, laxanteak edo katartikoak ez dira eraginkorrak metanol-intoxikazioan $(16,17,18)$.

Hasieran antidotoa (etanola) ematen hastea komeni da metanol-intoxikazio nabarmena (>30 $\mathrm{mL}$ helduetan eta $>0,4 \mathrm{~mL} /$ kghaurretan) susmatzen bada edota azidosi metabolikoa zein ezaugarri klinikoak antzematen badira, nahiz eta hartutako metanol-dosia edo odoleko metanol-maila ez jakin. Etanola aukerako tratamendutzat hartzen da. Ahotik zein zainbarnetik (bide zentraletik, osmolaritate handia duelako) eman daiteke. Alkohol deshidrogenasak metabolizatzen du eta entzima horrekiko 10 bider afinitate handiagoa du etanolak, metanolak baino, horrela inhibizio lehiakorra sortzen da bi alkohol horien artean toxikotasunaren erantzuleak diren metanolaren bi metabolitoen (formaldehidoa eta azido formikoa) eraketa blokeatuz. Tratamendu honek etanol plasmatikoaren balioak monitorizatzea eskatzen du. Eragin terapeutikoa lortzeko etanolaren plasma-maila 1-1,5 mg/mL-tan mantendu behar da.

Gaur egun, beste antidoto bat dago eskuragarri: fomepizola (4-metilpirazola). Alkohol deshidrogenasa entzimarekiko afinitatea metanolarena baino 80.000 aldiz handiagoa da eta etanolarena baino 8.000 aldiz handiagoa. Ez du efektu hepatotoxikorik sortzen eta etanolarekiko abantaila batzuk ditu: maneiatzeko erraza da, ahotik zein zain barnetik eman daiteke, ez du sedazioa handitzen, hipogluzemia eragiteko arrisku txikiagoa du eta gehiegizko likidoekin eta hemodinamikoki ezegonkorrak diren intoxikatuetan arazo gutxiago sortzen ditu. Fomepizolaren eragozpen nagusia kostu ekonomiko handia da (19-24). Hori dela eta, osasunzentro gehienetan oraindik ezin izan da erabiltzen hasi.

Tratamendurako bikarbonatoa erabiltzeak azidosi metabolikoa hobetzeaz gain, azido formikoa sortzea eragozten du. Odolean haren maila $18 \mathrm{mEq} / \mathrm{L}$ baino txikiagoa denean hasi behar da 
terapia. Batzuetan, beharrezkoa den bikarbonato kantitatea handia da (500-1.000 mEq/egun), pazienteek nahiko maiz 7tik beherako $\mathrm{pHa}$ baitute eta egoera horretan ez baitzaio bikarbonato-tratamenduari egoki erantzuten. Azido foliko gehigarria ere beharrezkoa da, azido formikoa $\mathrm{H}_{2} \mathrm{O}$ eta $\mathrm{CO}_{2}$ bihurtzeko kofaktorea baita, eta, horrela, begi-toxikotasunaren ondoriozko kalteen larritasuna murrizten delako. Azido folikoa metanola irentsi eta 10 ordura arteko tartean ematen bada, eraginkorra dela frogatu da. Metanola erauzteko neurrien artean hemodialisia da erabilgarriena, metanola eta haren metabolito toxikoak odoletik garbitzen baititu (25).

Gure ospitalean artatutako kasu ezberdinen maneiuan antzemandako zailtasunak direla eta, ebaluazio diagnostikoa behar bezala eta ahalik eta azkarren egiteko helburua jarri genuen. Azterketa-lan honetan ospitalean azken bi urteetan diagnostikatutako lau kasu bildu eta landu ditugu, elkarren artean zeharo ezberdinak. Antzekotasunak eta kasu bakoitzaren berezitasunak nabarmentzen ahalegindu gara, etorkizunean egon litezkeen metanol-intoxikazio kasuen maneiu-estrategia bateratzeko eta errazteko. Gaixo horien susmo diagnostikoari, datu kliniko eta analitikoei eta tratamenduari dagokien informazio garrantzitsuena aztertu dugu eta batzuetan zehazten zaila den diagnostiko goiztiarra ezartzeko estrategia baliagarria garatzeko beharra ikusi dugu, diagnostiko zuzen eta azkarrik ezean, tratamenduak ez baitu arrakastarik.

Lehen kasuak ohiko metanol-intoxikazioaren ezaugarriak zeuzkan: susmo diagnostikoa argia zen alkoholismo-aurrekariak, pozoitzearen zeinu eta sintoma ohikoenak eta diagnostikoa zehazteko beharrezko laborategiko emaitzak zituelako. Anion gap eta osmol gap emaitza altuak izan zituen gainera. Kasu horretan egoki eta azkar bideratu genuen diagnostiko kliniko eta analitikoa. Hori dela eta, tratamendua bizkor hasteko aukera izan zen. Metanol kantitate handia hartu zuen pazienteak, baina garaiz artatu zenez suspertzea lortu genuen. Tratamendua hartu osteko bigarren odol-lagin bat aztertzeko aukera egon zen eta metanola ia ez zen antzeman ere egin emakumearen odolean. Horrela ondorioztatu genuen diagnostiko klinikoa eta analitikoa azkarrak izan behar direla intoxikazio-kasuak oharkabean pasa ez daitezen.

Ospitalera iritsi orduko ateratako lehen odol-laginak funtsezkoak dira odolean dagoen toxikotasuna eta metanol-kontzentrazioa neurtzeko. Aurrerago edo tratamendua hasi ostean ateratako laginek diagnostikoa zaildu besterik ez dute egiten. Susmo klinikoa izatea nahikoa da metanol-intoxikazioari dagozkion odol-analisiak eskatzeko: gasometria eta oinarrizko biokimika bereziki, baita osmolalitate neurtua ere osmol gap balioa kuantifikatzeko. Lan honetan adierazi bezala, metanol-mailaren odoleko neurketa egitea da diagnostikoa konfirmatzeko era, baina gure ospitalean, gehientsuenetan bezala, ez dago metanola neurtzeko gas-kromatografia analisi-teknikarik eskuragarri. Horregatik, kontsentsuz erabaki da laborategi klinikoetan metanol-intoxikazioaren diagnostikoaren hurbilketa egiteko anion gap eta osmol gap kalkulatzea. Emaitza altuek ia zeharo baieztatzen dute diagnostikoa. Gure ospitalean osmol gap kalkulua metanol- eta etilenglikol-intoxikazioen susmoa dagoen kasu guztietan egiten da, bi kasuon tratamendua berbera delarik.

Testuan aipatutako bigarren eta hirugarren kasuak diagnostikatzeko orduan eragozpenak izan genituen. Bigarren gaixoa goizaldeko ordu txikietan ospitaleratu genuen ia koma-egoeran eta anamnesia eta azterketa fisikoa egiteko garaian zailtasunak egon ziren. Horrek odol-analisia atzeratu zuen eta osmolalitate neurtua ez zen neurtzerik izan, ondorioz osmol gap balioa kuantifikatu gabe geratu zen. Haren aurrekariak, ezaugarri klinikoak, azidosi metabolikoa eta anion gap altu iraunkorra kontuan hartuta, metanol-intoxikazioa izan zitekeela susmatu genuen, baina ordu gutxira hil egin zen. Hirugarren kasuan shock septikoa susmatu zen hasieran, ondorioz intoxikazioaren ondorioei aurre egiteko tratamendua apur bat berandu ezarri zitzaion eta ordurako metanolaren metabolizazio-prozesua oso aurreratuta zegoen.

Kasu horietan antzeman genuen metanol-intoxikazioaren susmoa batzuetan ez dela hain nabarmena izaten eta gaixoaren ezaugarri guztiak hartu behar direla kontuan: alkoholismo- 
aurrekariak; pozoitzearen mozkorraldi-zeinuak; sintoma gastrointestinal, bisual eta neurologiko ohikoak; eta odol-analisien emaitza esanguratsuenak $(\mathrm{pH}$ eta bikarbonato balio baxuak, eta laktato, anion gap eta osmol gap balio altuak). Bereziki osmol gap kalkulua ahalik eta azkarren egitea jarri genuen helburutzat eta orduz geroztik ospitalean artatutako kasuetan diagnostikoa garaiz zehazteko ezinbesteko datua izan da, tratamendua bizkor eta egoki ezartzeko aukera ematen baitigu. Laugarren kasua lanketa horren eredu izan zen, nahiz eta egoera kliniko larriaren erruz hil egin zen.

Gure ospitalean metanol-intoxikazio kasu guztietan segitzen den maneiu diagnostikoa eta terapeutikoa berbera izaten da. Zeinu klinikoak garrantzitsuak dira metanol-intoxikazioa susmatzeko. Koadro neurologikoa, shocka eta azidosi metaboliko larria nahikoak dira susmoa bideratzeko eta alkoholismo-aurrekariak, edo alkohol-kontsumoaren susmoak, are gehiago laguntzen du diagnostikoa zehazten. Oinarrizko tratamenduari hasiera eman behar zaio eta odol-analisia ere egiten da. Osmol gap emaitza altuak, metanol-neurketarik ezean, diagnostikoa bideratzen du. Neurri terapeutikoen artean zainbarneko etanola da jartzen den aurrenetakoa, metanol-intoxikazioaren antidoto gisa. Fomepizola eraginkorragoa izan arren, ez dugu eskuragarri ospitalean. Etanolarekin batera bikarbonatoa jartzen da azidosi metabolikoak eragindako shockari aurre egiteko, baita azido folikoa eta hemodialisia ere kasu larri guztietan. Ospitaleratutako intoxikatu gehienak oso larri egoten dira, hortaz metanola eta bere metabolito toxikoak odoletik garbitzeko neurririk erabilgarriena hemodialisia da. Kasu arinetan saihets liteke, baina shocka, kalte neurologikoa eta azidosia bada beti erabiltzen dugu hemodialisia.

Aztertutako lau adibide hauetan ikusi dugu osmol gap kalkuluaren analisia egitea erabakigarria izan daitekeela diagnostikoa zuzen bideratzeko. Beraz, ezinbestekotzat jotzen dugu osmol gap probari balioa ematea eta haren analisia sustatzea metanol-intoxikazioaren diagnostikoa garaiz zehazteko, horrek tratamenduaren arrakasta bermatzen duelako.

\section{Ondorioak}

Metanol-intoxikazioa interes toxikologiko handiko arazoa da gaur egun. Azidosi metaboliko larriak eta anion gap eta osmol gap balio altuek osasunerako kaltegarriak diren konplikazio ugari eta heriotza bera ere azkar eragin ditzakete. Azidosiak eta zeinu eta sintoma neurologikoek, aurrekariekin batera, metanol-intoxikazioaren susmoa piztu behar digute. Funtsezkoa da diagnostikoa garaiz zehaztea tratamendua ahalik eta azkarren ezartzeko; izan ere, antidoto eta hemodialisi bidezko tratamenduak eraginkortasuna galtzen du metanola metabolizatu egin bada.

Laborategi klinikoaren eginkizuna erabakigarria da metanol-intoxikazio kasuen diagnostiko goiztiarrean: odol-analisien emaitza larriak ohartaraziz, anion gap zein osmol gap gisako laborategikalkulu baliagarriak egiteko aukera eskainiz eta emaitza horien inguruko zalantzak argituz. Ospitaleetako laborategi gehientsuenetan ez dago metanola neurtzeko analisi-teknika espezifikorik eskuragarri, eta horregatik da garrantzitsua aipatutako laborategiko proba horiek azkar egitea eta behar bezala interpretatzea.

Metanol-intoxikazioaren diagnostikoa garaiz eta zuzen zehazteko osmol gap kalkuluaren analisia egitea erabakigarria izan daitekeela ondorioztatu dugu. Hori dela eta, ezinbestekoa deritzogu Laborategiko, Larrialdietako eta Zainketa Intentsiboko osasun-profesionalen artean harreman estua eta komunikazio eraginkorra izateari prozesu diagnostikoak irauten duen denbora osoan.

\section{Eskerrak eta oharrak}

Lan hau Donostia Unibertsitate Ospitaleko Analisi Klinikoen Zerbitzuaren, Larrialdi Zerbitzuaren eta Zainketa Intentsiboko Unitatearen arteko lankidetzari esker egin da. 
Beñat de Alba I., Noelia Lopez B., Eztitxu Gaztelumendi E., Felix Zubia O., Ma Asuncion Vives

A., Eva Lorea Gil R., Miren Arantza Aguillo G., Jesus Barado H.

\section{Erreferentzia bibliografikoak}

1. Nolla-Salas J, Nogué Xarau S, Marruecos Sant L, Palomar Martínez M, Martínez Pérez J. Intoxicación por metanol y etilenglicol. Estudio de 18 observaciones. Med Clin. 1995; 104:121-125.

2. Kruse JA. Methanol poisoning [Internet]. Intensive Care Med. 1992 [Kontsulta: 202005-20]; 18:391-397. Eskuragarri: https://doi.org/10.1007/BF01694340

3. Trummel J, Ford M, Austin P. Ingestion of an unknown alcohol [Internet]. Ann Emerg Med. $1996 \quad$ [Kontsulta: 2020-05-20]; 27:368-374. Eskuragarri: https://doi.org/10.1016/s0196-0644(96)70274-3

4. Bennett JL, Cary FH, Mitchell GL, Cooper MN. Acute methyl alcohol poisoning: A review based on experiences in an outbreak of 323 cases [Internet]. Medicine. 1953 [Kontsulta: 2020-05-20]; 32(4):431-463. Eskuragarri: https://doi.org/10.1097/00005792195312000-00002

5. Liesivuori J, Savolainen H. Methanol and formic acid toxicity: biochemical mechanisms [Internet]. Pharmacol Toxicol. 1991 [Kontsulta: 2020-05-20]; 69:157-163. Eskuragarri: https://doi.org/10.1111/i.1600-0773.1991.tb01290.x

6. Fontenot AP, Pelak VS. Development of neurologic symptoms in a 26 year old woman following recovery from methanol intoxication [Internet]. Chest. 2002 [Kontsulta: 202005-20]; 122:1436-1439. Eskuragarri: https://doi.org/10.1378/chest.122.4.1436

7. Hovda KE, Mundal H, Urdal P, McMartin K, Jacobsen D. Extremely slow formate elimination in severe methanol poisoning: a fatal case report [Internet]. Clin Toxicol (Phila). $2007 \quad$ [Kontsulta: 2020-05-20]; 5:516-521. Eskuragarri: https://doi.org/10.1080/15563650701354150

8. Hovda KE, Hunderi OH, Rudberg N, Froyshov S, Jacobsen D. Anion and osmolal gaps in the diagnosis of methanol poisoning: clinical study in 28 patients [Internet]. Intensive Care Med. 2004 [Kontsulta: 2020-05-20]; 30:1842-1846. Eskuragarri: https://doi.org/10.1007/s00134-004-2373-7

9. Kraut JA, Madias NE. Serum anion gap: Its uses and limitations in clinical medicine [Internet]. Clin J Am Soc Nephrol. 2007 [Kontsulta: 2020-05-20]; 2:162-174. Eskuragarri: https://doi.org/10.2215/CJN.03020906

10. Glaser DS. Utility of the serum osmol gap in the diagnosis of methanol and ethylene glycol ingestion [Internet]. Ann Emerg Med. 1996 [Kontsulta: 2020-05-20]; 27:343-346. Eskuragarri: https://doi.org/10.1016/s0196-0644(96)70271-8

11. Church AS, Witting MD. Laboratory testing in ethanol, methanol, ethylene glycol, and isopropanol toxicities [Internet]. J Emerg Med. 1997 [Kontsulta: 2020-05-20]; 15:687692. Eskuragarri: https://doi.org/10.1016/s0736-4679(97)00150-9

12. Prabhakaran V, Ettler $\mathrm{H}$, Mills A. Methanol poisoning: two cases with similar plasma methanol concentrations but different outcomes [Internet]. CMAJ. 1993 [Kontsulta: 2020-05-20]; 148:981-984. Eskuragarri: https://www.ncbi.nlm.nih.gov/pmc/articles/PMC1490736/pdf/cmaj00307-0131.pdf 
13. Höjer J. Severe metabolic acidosis in the alcoholic: Differential diagnosis and management [Internet]. Hum Exp Toxicol. 1996 [Kontsulta: 2020-05-25]; 15:482-488. Eskuragarri: https://doi.org/10.1177/096032719601500604

14. Fujita M, Tsuruta R, Wakatsuki J, Takeuchi H, Oda Y, Kawamura Y, Yamashita S, Kasaoka $\mathrm{S}$, Okabayashi K, Maekawa T. Methanol intoxication: differential diagnosis from anion gap-increased acidosis [Internet]. Internal Med. 2004 [Kontsulta: 2020-05-25]; 43:750754.

Eskuragarri: https://www.jstage.jst.go.jp/article/internalmedicine/43/8/43 8 750/ pdf/-char/en

15. Liu JJ, Daya MR, Carrasquillo O, Kales SN. Prognostic factors in patients with methanol poisoning [Internet]. J Toxicol Clin Toxicol. 1999 [Kontsulta: 2020-05-25]; 36:175-181. Eskuragarri: https://doi.org/10.3109/15563659809028937

16. Barceloux DG, Bond GR, Krenzelok EP, Cooper H, Vale JA; American Academy of Clinical Toxicology Ad Hoc Committee on the Treatment Guidelines for Methanol Poisoning. American Academy of Clinical Toxicology practice guidelines on the treatment of methanol poisoning [Internet]. J Toxicol Clin Toxicol. 2002 [Kontsulta: 2020-05-25]; 40:415-446. Eskuragarri: https://doi.org/10.1081/clt-120006745

17. Abramson S, Singh AK. Treatment of the alcohol intoxications: ethylene glycol, methanol and isopropanol [Internet]. Curr Opin Nephrol Hypertens. 2000 [Kontsulta: 2020-05-25]; 9:695-701. Eskuragarri: https://doi.org/10.1097/00041552-200011000$\underline{00017}$

18. Kraut JA. Approach to the treatment of methanol intoxication [Internet]. Am J Kidney Dis. 2016 [Kontsulta: 2020-05-25]; 68:161-167. Eskuragarri: https://doi.org/10.1053/j.ajkd.2016.02.058

19. Jacobsen D, McMartin KE. Antidotes for methanol and ethylene glycol poisoning [Internet]. J Toxicol ClinToxicol. 1997 [Kontsulta: 2020-05-25]; 35:127-143. Eskuragarri: https://doi.org/10.3109/15563659709001182

20. Brent J, McMartin K, Phillips S, Aaron C, Kulig K; Methylpyrazole for Toxic Alcohols Study Group. Fomepizole for the treatment of methanol poisoning [Internet]. N Engl J Med. 2001 [Kontsulta: 2020-05-25]; 344:424-429. Eskuragarri: https://doi.org/10.1056/NEJM200102083440605

21. Mégarbane B, Borron SW, Trout H, Hantson P, Jaeger A, Krencker E, Bismuth C, Baud FJ. Treatment of an acute methanol poisoning with fomepizole [Internet]. Intensive Care Med. 2001 [Kontsulta: 2020-05-25]; 27:1370-1378. Eskuragarri: https://doi.org/10.1007/s001340101011

22. Hovda KE, Andersson KS, Urdal P, Jacobsen D. Methanol and formate kinetics during treatment with fomepizole. Clin Toxicol. 2005; 43:221-227.

23. Rietjens SJ, de Lange DW, Meulenbelt J. Ethyleneglycol or methanol intoxication: which antidote should be used, fomepizole or ethanol? [Internet]. Neth J Med. 2014 [Kontsulta: 2020-05-25]; 72:73-79. Eskuragarri: http://www.njmonline.nl/getpdf.php?id=1410

24. Zakharov S, Pelclova D, Navratil T, Belacek J, Komarc M, Eddleston M, Hovda KE. Fomepizole versus ethanol in the treatment of acute methanol poisoning: comparison of clinical effectiveness in a mass poisoning outbreak [Internet]. ClinToxicol (Phila). 
Beñat de Alba I., Noelia Lopez B., Eztitxu Gaztelumendi E., Felix Zubia O., Ma Asuncion Vives A., Eva Lorea Gil R., Miren Arantza Aguillo G., Jesus Barado H.

2015 [Kontsulta: 2020-05-25]; 53:797-806. Eskuragarri: https://doi.org/10.3109/15563650.2015.1059946

25. Chow MT, Di Silvestro VA, Yung CY, Nawab ZM, Leehey DJ, Ing TS. Treatment of acute methanol intoxication with hemodialysis using an ethanol-enriched, bicarbonate-based dialysate [Internet]. Am J Kidney Dis. 1997 [Kontsulta: 2020-05-25]; 30:568-570. Eskuragarri: https://doi.org/10.1016/s0272-6386(97)90318-8 